\title{
Temporalidades no trânsito urbano de Manaus
}

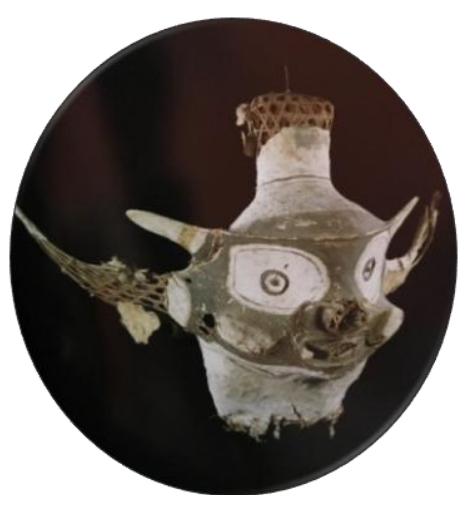

Karina Gonçalves Teixeira da Silva ${ }^{1}$ Gláucio Campos Gomes de Matos ${ }^{2}$

\section{Resumo}

Este artigo tem como objetivo fazer uma reflexão sobre a importância de compreender o tempo nos diferentes níveis coexistentes no trânsito de Manaus. O trabalho parte de uma abordagem qualitativa, com pesquisa bibliográfica embasado na Teoria Sociológica de Norbert Elias em sua obra Sobre o Tempo. A observação do cotidiano no trânsito de Manaus coadunou com o referencial teórico. As figurações nas quais as pessoas estão inseridas, o aumento de veículos e a incompatibilidade das estruturas mexem com a dinâmica temporal das pessoas quando inseridas no trânsito. Dessa forma, o tempo é uma categoria a ser levada em consideração ao ser estudado o trânsito em Manaus.

Palavras-chave: Trânsito. Tempo. Sociedade. Interdependência.

\begin{abstract}
This article aims to understand the time as symbolic element of social organization in different coexisting levels in Manaus transit. The work of a qualitative approach, bibliographical research based in the Sociological Theory of Norbert Elias in his book about Time. The observation of daily life in Manaus traffic conformed to the theoretical framework. The figurations in which people are inserted, the increase of vehicles and the incompatibility of stir structures with the temporal dynamics of people when inserted in traffic. Thus, time is a category to be taken into account when studying the traffic in Manaus.
\end{abstract}

Keywords: Traffic. Time. Society. Interdependence.

\footnotetext{
${ }^{1}$ Mestranda em Sociedade e Cultura da Amazônia (PPGSCA-IFCHS-UFAM)

2 Professor do Programa de Pós-Graduação Sociedade e Cultura na Amazônia da Universidade Federal do Amazonas.
} 


\section{INTRODUÇÃO}

No desenvolvimento das sociedades complexas, a mobilidade urbana e especificamente o trânsito nas grandes cidades, tem merecido atenção especial por parte dos indivíduos que estão inseridos neles e por parte dos agentes e engenheiros de trânsito.

Nesse desenvolvimento houve aumento de acidentes e mortes no trânsito das grandes cidades e rodovias de todo o Brasil. Com o objetivo de melhorar essa mobilidade, presenciamos a construção de estradas, viadutos, avenidas, encostamentos e calçadas para a melhor ocupação dos espaços pelos veículos e transeuntes. Concomitantemente vimos a necessidade de um ordenamento do tráfego para evitar o desconforto, o perigo à vida das pessoas. Essas estruturas foram erguidas, mas o que é pouco se ver dar atenção nas questões do trânsito é do tempo, elemento simbolicamente concebido pelos homens e que atua, em seus criadores, em vários momentos da vida, como um mecanismo de coação e no trânsito, ele não deixa de ser percebido.

No processo civilizador, o avanço dos meios de transporte, demandou a criação de símbolos - faixas de pedestres, semáforos, radares, placas de sinalização - universais de compreensão social para orientar tanto o motorista, quanto o pedestre, no trânsito. Em virtude de alguns estados e nações, a exemplo do Brasil, não terem eficiência em colocar os mecanismos de controle em execução plena, ocorrem as constantes infrações, acidentes e muitas mortes no trânsito.

Hoje, os meios de transporte fazem parte das nossas vidas, como uma extensão de nós mesmos, ao ponto de não conseguirmos mais viver sem eles. Essa dependência tem raiz no status social, na deficiência dos transportes públicos e na necessidade de maior mobilidade humana. Um olhar mais atento, podemos perceber que somos parte do trânsito. Para irmos ao trabalho, escola, lazer, seja de automóvel, ônibus ou a pé 
utilizamos as ruas, avenidas, viadutos, passarelas calçadas, estradas. A roupa que vestimos, a comida que comemos, o combustível dos automóveis, tudo que consumimos em grande parte chega até nos por meio do trânsito. Ao mesmo tempo que os veículos nos proporcionam comodidade, negócios, status social também são responsáveis pelas tensões vividas diariamente nos enormes congestionamentos urbanos, das dificuldades de encontrar vagas de estacionamento, dos pedestres em busca de espaço nas calcadas, a falta de segurança dos motociclistas e ciclistas e da precariedade dos sistema de transporte coletivo que não consegue atender a demanda dos usuários das grandes cidades, sem contar os problemas ambientais que acarretam. Mas, é o tempo a nós instigar, pois de alguma forma, a convergência de pessoas, os encontros, reuniões, trabalho estão vinculados ao tempo.

As regiões metropolitanas em todo o mundo vivem o problema dos congestionamentos urbanos. A sensação de tempo perdido diante dos enormes congestionamentos é vivida diariamente por milhares de brasileiros. Em Manaus, as principais vias de acesso estão esgotadas e a cada mês, 5 mil novos veículos entram em circulação, segundo o Departamento Estadual de Trânsito - Detran-AM . Considerando que Manaus não foi planejada para absorver quantidade inesperada de veículos particulares, os congestionamentos são constantes, impactando na qualidade de vida das milhares de pessoas que circulam diariamente pela cidade e querendo ou não acelerando ou retardando o tempo simbólico das pessoas.

É nesse contexto que a questão referente ao tempo no trânsito merece uma reflexão, considerando que vivemos em uma sociedade complexa e plural que obedece ao tempo social criado pelos indivíduos e imposto pelas figurações que eles formam. O tempo não pode ser perdido, é dinheiro, mas que entre os indivíduos no trânsito das capitais amazônicas, o tempo é aferido e interpretado nas diversas figurações. Para isso faremos um percurso pelos conceitos de tempo, figurações e relações 
de interdependência com base na teoria de Norbert Elias tendo como objeto o tempo no trânsito de Manaus e os usuários que por ele transitam diariamente. Captar a ambigüidade do tempo como necessário para a vida em sociedade e também como possível causador de sofrimento para a mesma, é buscar compreendê-lo em seus múltiplos aspectos e dinâmicas. "compreender sua própria experiência do tempo é, também, compreender a si mesmo"

\section{Conceitos clássicos sobre o Tempo}

Em Elias (1998) podemos observar que o tempo, tal qual percebemos hoje é resultado de processo de aprendizagem. Ao longo da história do Ocidente e com as mudanças da sociedade, dos grupos que sequer possuíam uma noção do tempo até os que o concebem da forma sistematizada, como a sociedade capitalista contemporânea, a palavra tempo foi adquirindo diferentes definições, de acordo com a necessidade de orientação da vida prática. As concepções clássicas sobre o tempo procuram fragmentá-lo colocando o em posições opostas.

Os objetivistas sustentavam que o tempo é um dado objetivo da natureza, algo real e é a dimensão onde as coisas existem e acontecem. Está estreitamente vinculado ao tempo cosmológico, ao tempo do universo, dos astros. Se confunde com os movimentos regulares dos corpos celestes que geram o dia e a noite. O tempo seria a articulação desses movimentos, a duração do mundo medida por esses movimentos. Para eles não há nenhum mistério em relação ao tempo, ele é determinável e quantificável, é a medida dos movimentos comuns a partir de uma referência comum. Seja ele absoluto como para Newton ou relativo como para Einstein, ele tem sua forma objetiva de existência na natureza. Já para os subjetivistas, vinculados à filosofia, concebem o tempo como um dado a priori da consciência, desenvolvido durante a formação psicológica do ser humano e 
que o acompanha durante toda sua vida, possibilitando a ordenação da vida diante do devir dos acontecimentos. Ele não é exterior à consciência, não pode existir fora dela. Seus principais representantes: Parmênides, Platão, Plotino, Santo Agostinho, São Tomás, Kant, Descartes, Leibniz, Hegel, Husserl, Heidegger, Bergson e Bachelard. (SILVA apud REIS 1994)

“O tempo é o começo do movimento da alma em direção às coisas sensíveis, é sua vida, que produz o tempo. Essa sua ação constitui o tempo e o universo. O tempo em si não é uma medida. Ou melhor, não se reduz a uma medida, embora possa ser medido de alguma forma pelos movimentos dos astros. Esse movimento indica o tempo, mas não o engendra. O tempo é o movimento da alma universal.(SILVA apud REIS, 1994: p.30). Essa dicotomia entre o universo natural e universo humano das teorias clássicas, foi severamente criticada por Elias e responsável pela concepção do Tempo Social

Segundo Elias (1998) ao longo dos séculos, essa foi uma busca inútil. Partiu-se à caça de algo que não existe, ou seja, do "tempo", entendido como realidade universal, uma realidade dada a todos os homens do mesmo modo e experimentada por todos da mesma maneira. Ao dirigir seu questionamento para tal "objeto", os pensadores caíram incessantemente na armadilha que eles mesmos se prepararam. Vez após outra, viram-se obrigados a escolher entre dois postulados fundamentais relativos ao "tempo", ambos igualmente especulativos e impossíveis de demonstrar. (Elias, 1998: p. 99)

\section{O Tempo Social de Norbert Elias}

Por que quando somos criança o tempo parece mais lento e quando adultos o tempo voa? Essas e muitas outras indagações sobre o tempo sempre estiveram presentes em nossas vidas e a ciências há centenas de anos tenta nos responder. 
Não podemos tocar, olhar, ouvir ou saborear o tempo, mas sabemos hoje muito mais do que antes que ele está presente em todos os momento de nossa vida, desde o nascimento até a morte. Todas as atividades realizadas pela sociedade contemporânea estão diretamente ligadas ao tempo macro do calendário e micro do relógio. As pessoas têm hora para dormir, acordar, fazer as refeições, trabalhar, divertir-se. No curso do processo civilizador (Elias 1994), podemos constatar o efeito do tempo na vida do indivíduo. A criança é levada, desde cedo a compreender o efeito do tempo nas relações sociais. Matos (2015, pg 38), mostra que de acordo com as regras sociais, a criança desde cedo tem que controlar sua natureza, dentre eles os esfíncteres da bexiga, ânus e vagina. Nesse caso o tempo age como um autocontrole de fora para dentro. Em Elias, (1989, p. $64,65)$, no processo civilizador quanto mais ampla e interdependente for a ação humana, maior será sua dependência do tempo constituído simbolicamente.

O tempo é elemento imprescindível na coordenação e integração das relações sociais. $\mathrm{Na}$ modernidade, com crescente urbanização e comercialização, o número de atividades a serem sincronizadas é cada vez maior e complexo. Nas configurações o tempo é padronizado para a organização das rotinas diárias. Medições do tempo permitem ao homem uma regularidade e previsibilidade diante da vida, movimento e atividade.

Segundo Elias, relógios são as invenções humanas que incorporadas no mundo simbólico do homem possibilitaram a integração de aspectos físicos, biológicos, sociais e subjetivos. Os relógios são invenções humanas e não uma existência natural. Em um mundo sem homens e seres vivos, não haveria tempo, relógios e calendários. (Elias, 1998)

Os calendários são de períodos primitivos, nos quais sacerdotes e espirituosos saíam a proclamar o aparecimento de uma nova lua, anunciando o início de um novo mês. Diferentes dos usados antigamente, 
os calendários atuais são globais com a divisão do tempo em semanas, meses, anos, séculos, dias de trabalho, dias de descanso, feriados, datas comemorativas, quatro estações e fases da lua. Essas formas simbólicas de medição do tempo trouxeram previsibilidade e padronização diante de irreversibilidade de nosso mundo, é o que aponta Elias (1998).

Na perspectiva de Elias o homem é construtor do tempo, um não se compreende sem o outro. Quando se resgata historicamente o tempo, o homem pode repensar sua vida e transformá-la à medida que é sujeito do processo de construção da própria história e também do tempo, porém, não quer dizer que haja uma bola de cristal. Pois é no planejamento dos homens que desencadeia, segundo Elias (1994) um processo cego. Pelo fato de o ser humano não nascer com um sentido temporal pronto, organizações temporais devem que ser aprendidas juntamente com outros aspectos culturais. A aprendizagem do tempo numa sociedade industrializada requer anos para se desenvolver, para que o sujeito decifre o complexo sistema simbólico temporal que regula a vida social. Esse sistema, também influencia nosso modo de olhar diante da realidade.

Outro aspecto importante, que Elias menciona em sua obra Sobre o Tempo é que com o processo civilizador, a coerção externa transformou-se em coerção auto-imposta e o tempo passou a impor seu domínio externamente e, principalmente, internamente, ou seja, o tempo passou a exercer uma função coercitiva sobre nós, fenômeno esse vivenciado, dada as figurações as quais os indivíduos estão inseridos, diariamente no trânsito das grandes cidades.

Assim, como tempo, homem e natureza não são dissociáveis. Para Elias, tempo e espaço também devem ser estudados conjuntamente porque estão imbricados. De acordo com ele "tempo e espaço são símbolos conceituais de tipos específicos de atividades sociais e institucionais. Eles possibilitam uma orientação com referência às posições, ou aos intervalos entre essas posições, ocupadas pelos acontecimentos“. (Elias, 1998, pg 80) 
Portanto, para compreender o tempo no contexto onde esse é produzido, deve-se considerar o espaço como relevante na configuração das relações sociais.

\section{Configuração do espaço urbano}

A teoria sociológica de Elias (1980) concebe sua tarefa como a de analisar os processos sociais baseados nas atividades dos indivíduos que, através de suas disposições básicas, ou seja, suas necessidades, são orientados uns para os outros e unidos uns aos outros das mais diferentes maneiras. Esses indivíduos constroem teias de interdependência que dão origem a configurações de muitos tipos: família, cidade, estado, nações e o trânsito que aqui se apresenta como, objeto desse estudo. O conceito de configuração pode ser aplicado onde quer que se formem conexões e teias de interdependência humana, isto é, em grupos relativamente pequenos ou em agrupamentos maiores. Este conceito busca amenizar o abismo existente entre indivíduo e sociedade, que foi historicamente constituído. Portanto, compreendendo a sociedade formada por indivíduos ligados a teias de interdependência, fica mais visível entendermos a configuração urbana das cidades.

Segundo Vasconcellos, em cada cidade se materializa um sistema espacial complexo, compreendendo uma montagem interdependente de áreas funcionais (privadas e públicas). Estas áreas podem ser denominadas tanto como espaço de produção (no qual o processo de acumulação ocorre) ou de reprodução (no qual a recuperação da força de trabalho ocorre). Ambos os espaços são mediados por um terceiro espaço, dedicado às necessidades de circulação. (SOUZA 2009, apud Vasconcellos, 1998)

As áreas funcionais de produção são aquelas ocupadas com atividades industriais, comerciais e de serviços (inclusive administrativas). Já as áreas destinadas à reprodução são os espaços de moradia (casas, 
apartamentos, barracos, etc.) e ambientes de lazer (parques, praças públicas praias, clubes, etc). Fazendo a conexão entre estes dois diferentes espaços há um terceiro: o da circulação. É através deste que as pessoas se deslocam para produzir ou reproduzirem-se e as matérias-primas, produtos e serviços são levados de um espaço a outro, entretanto, as pessoas não agem isoladamente em cada espaço, elas se ligam por teias de interdependências, no qual o tempo é um elemento fundamental dessas relações. "A interdependência verifica-se também por intermédio da jornada para o trabalho, articulando locais de moradia e locais de trabalho. (SOUZA, 2009, apud Corrêa, 2007)

\section{Mobilidade e acessibilidade}

A densidade demográfica exerce forte influência sobre a acessibilidade e mobilidade da população urbana. Ela é função do número de habitantes por unidade de área e determina, em última instância, a extensão dos deslocamentos urbanos. A extensão e o custo médio das viagens urbanas são inversamente proporcionais à densidade demográfica. Isto é: quanto menor a densidade, maior a dispersão, o custo e o tempo médio das viagens urbanas. Densidades menores geram deseconomias urbanas e prejuízos ambientais. Acima disso passam a apresentar problemas relacionados à circulação, ao abastecimento, etc.(SOUZA, 2009)

Para Vasconcellos (SOUZA 2007, apud Vasconcellos, 1998) a acessibilidade não pode ser vista apenas como a habilidade para movimentar-se sobre o espaço urbano, mas deve incluir também aspectos relacionados à acessibilidade econômica dos meios de circulação, bem como da compatibilização entre o tempo disponível dos indivíduos e as horas de operação das atividades de destino das viagens. Segundo a Lei Federal 12.581/ 2012, mobilidade urbana é considerada a condição em que se realizam os deslocamentos de pessoas e cargas no espaço urbano. 
Já a mobilidade diz respeito às condições das pessoas em se movimentar sobre o espaço urbano, utilizando os espaços e recursos disponíveis (e acessíveis) de circulação.

A Secretaria Nacional de Transporte e da Mobilidade Urbana SeMOB - ligada ao Ministério das Cidades, entende que mobilidade urbana é "a reunião das políticas de transporte e de circulação, e integrada com a política de desenvolvimento urbano, com a finalidade de proporcionar o acesso amplo e democrático ao espaço urbano, priorizando os modos de transporte coletivo e os não-motorizados, de forma segura, socialmente inclusiva e sustentável".

A mobilidade urbana dessa forma compreende a construção de um sistema integrado que garanta a facilidade aos cidadãos hoje e no futuro, o acesso físico às oportunidades e às funções econômicas e sociais das cidades, porém a questão do tempo não é discutida, condição essa essencial, já que as pessoas estão inseridas em figurações de diversos níveis no seio da mobilidade urbana.

A SeMOB considera ainda que a mobilidade deve ser centrada nas pessoas que transitam possibilitando a todos a satisfação individual e coletiva de atingir os destinos desejados, as necessidades e prazeres cotidianos.

Porém, nesse entendimento, a compreensão da categoria figuração ajuda no sentido de que os indivíduos estão ligados em redes de interdependências funcionais em vários níveis onde o tempo exerce a função de convergência.

\section{Trânsito}

O trânsito, um dos principais problemas urbanos de médias e grandes cidades é a concretização da mobilidade da população urbana e a circulação de mercadorias e serviços. Para Vasconcellos (SOUZA 2007, 
apud Vasconcellos, 1998) “o trânsito é o conjunto de todos os deslocamentos diários, feitos pelas calçadas e vias da cidade, e que aparece na rua na forma da movimentação geral de pedestres e veículos”

Segundo o Código Brasileiro de Trânsito (CTB) Art. $1 \int 1^{\circ}$ Considera-se trânsito a utilização das vias por pessoas, veículos e animais, isolados ou em grupos, conduzidos ou não, para fins de circulação, parada, estacionamento e operação de carga ou descarga. No Art. $2^{\circ}$ o CBT considera vias terrestres urbanas e rurais as ruas, as avenidas, os logradouros, os caminhos, as passagens, as estradas e as rodovias, que terão seu uso regulamentado pelo órgão ou entidade com circunscrição sobre elas, de acordo com as peculiaridades locais e as circunstâncias especiais.

Para que exista o trânsito é necessário que as vias sejam utilizadas por pessoas, veículos e animais. A esse conjunto chamamos de usuários do trânsito. Não importa se os veículos estejam sendo conduzidos ou não, basta estar numa via terrestre.

\section{Manaus - Configuração do espaço urbano, mobilidade, acessibilidade e trânsito}

Para entender a realidade atual do transporte e do trânsito urbanos de Manaus, precisamos voltar no tempo recuperar parte da história recente desta cidade em seu aspecto mais imediato - em relação ao projeto nesta cidade implantado efetivamente a partir da década de 1970 - a Zona Franca de Manaus.

Com o declínio da economia da borracha no início do século passado a grande depressão na qual a cidade mergulhou somente foi interrompida com a implantação do projeto Zona Franca de Manaus, no início dos anos de 1970. Sob a influência deste projeto, Manaus passou a registrar elevados índices de crescimento demográfico. As transformações decorrentes deste projeto, notadamente a expansão e o arranjo do sítio urbano, bem como a insuficiência de recursos destinados à expansão e 
adequação da estrutura viária em níveis compatíveis com o porte que a cidade viria a assumir, determinaram as condições de transportes e trânsito urbanos enfrentados atualmente pela cidade. Pode-se dizer, de acordo com Barros (2007), que Manaus é uma cidade orgânica1, na medida em que sua expansão procurou adaptar-se às condições sócio-econômicas e ambientais locais.

Em Barros (2007) podemos compreender que a cidade é formada por água ao oeste, sul e leste e que a cidade de Manaus somente pôde crescer na direção norte e, sem reservar áreas para circulação à margem do rio Negro, conta com poucas vias de acesso à área central. Assim, expandindo horizontalmente para o norte, a mancha urbana cresceu em ritmo mais acentuado que sua população (reduzindo a densidade demográfica e aumentando a extensão das viagens) e não se preparou para assegurar níveis satisfatórios de mobilidade à sua população. A ausência de conexão das ruas entre os bairros reduz as alternativas de circulação, concentrando boa parte do fluxo de veículos a poucas e tortuosas vias.

Devido a pouca atenção dedicada pelo Estado, o sistema viário de Manaus cresceu como consequência do crescimento da moradia, de forma insuficiente e inadequada. O poder público, ao invés de estar à frente do processo de crescimento da cidade e do sistema viário, esteve atrás destes. Bairros formados "espontaneamente", somente passaram a contar com ações do Estado após sua consolidação, levando pavimentação em vias para passar o ônibus do transporte coletivo e a coleta do lixo.

1 Cidades orgânicas são aquelas que vão se formando e crescendo mais ou menos à maneira dos organismos vivos, adaptando-se a um terreno em que se viram inseridas de maneira não planejada, e sobretudo fazendo concessões permanentes à vida em toda a sua imprevisibilidade. Estas cidades modificam os seus traçados para se adaptar a um rio que lhes serve de fronteira, contornam morros ou os absorvem, sobem e descem ladeira de variados tamanhos. Suas ruas organizam-se livremente para atender mais aos chamados da vida cotidiana que aos planejamentos previamente estabelecida. 
Os Planos Diretores Urbanos são tidos como importantes instrumentos para orientar e disciplinar o crescimento urbano, mas infelizmente não são colocados em prática, o que compromete o ordenamento estrutural da cidade. Atualmente Manaus esta sob a vigência da Lei Complementar no 02 de 16 de janeiro de 2014 que institui o Plano Diretor Urbano e Ambiental do Município de Manaus, considerando o disposto na Lei Federal no 12.587, de 3 de janeiro de 2012, que instituiu as diretrizes da Política Nacional de Mobilidade Urbana

Do ponto de vista da mobilidade da população pode-se dizer que a cidade tem voltado sua atenção privilegiadamente para modos de transporte motorizados de duas e quatro rodas, com destaque para o automóvel particular e o transporte coletivo por ônibus. Apesar de ladeada pelo rio Negro e igarapés, não há a participação do modo hidroviário no transporte de passageiros urbanos, que seria uma alternativa viável para minimizar os efeitos dos congestionamentos no trânsito e o efeito coercitivo no tempo na vida das pessoas que estão inseridas nas mais variadas figurações que movem o trânsito urbano de Manaus.

Como podemos perceber na mobilidade da população de Manaus há um "gasto" de tempo no trânsito, por passageiros de diferentes modos de transporte. Com base nos estudos realizados pela atual Prefeitura de Manaus para a elaboração do Projeto de Mobilidade Urbana 2015 estima-se que o tempo consumido diariamente pela população em circulação em ônibus e automóveis é de 1,1 milhões de horas.

Ainda com base nos estudos da Prefeitura de Manaus (2015) pode-se verificar que os usuários de ônibus, de classes de menor renda, terminam por serem os mais prejudicados, haja vista que respondem por $53 \%$ das viagens diárias e por $74 \%$ do tempo total gasto pela Sociedade. Isto se mostra evidente, na comparação das velocidades de circulação nas horas de pico. Enquanto os motoristas de automóveis circulam a uma velocidade média na cidade de $31 \mathrm{~km} / \mathrm{h}$, os usuários de ônibus, o fazem a 
$17,6 \mathrm{~km} / \mathrm{h}$. Estes, entretanto, ainda precisam aguardar os ônibus e caminhar na origem e no destino da viagem. Considerando o tempo de viagem total, os que usam automóveis consomem em média 20 minutos em suas viagens, contra 50 minutos dos usuários de ônibus.

Há necessidade de averiguar ainda o tempo gasto pelos motociclistas em seus percursos. O que tem levado a população em busca da aquisição dos veículos de duas rodas: seria o fator econômica ou fator tempo?

O espaço viário ocupa boa parte do espaço urbano. É construído e mantido pelo poder público através da arrecadação de impostos. Destinase sobretudo à circulação de produtos, pessoas e serviços. Por outro lado, a construção e manutenção das calçadas - que respondem por quase um terço das viagens urbanas e teoricamente é o espaço privilegiado para a circulação dos pedestres - são de responsabilidade dos proprietários dos imóveis. Ao observarmos a diferença entre a rua e a calçada constata-se como Manaus tem sido planejada, construída e mantida para privilegiar os modos motorizados de transporte, em detrimento da marcha a pé. Reforça esta compreensão, o fato de que o poder público deveria destinar recursos humanos para fiscalizar e cobrar a observância dos dispositivos legais referentes às calçadas.

A população estimada em Manaus para 2016 é de 2.094.391 habitantes, conforme dados do Instituto Brasileiro de Geografia e Estatística (IBGE). Abriga aproximadamente uma frota de 650 mil veículos (cerca de 4 hab/veículo) e 15 mil vias.

Em Manaus três grandes áreas geradoras de viagens urbanas: a zona central, que concentra atividades de comércio e serviços; as zonas oeste, norte e leste (residenciais) e o distrito industrial (atividades industriais), localizado na porção sudeste da cidade.

Devido ao crescimento populacional dos últimos dez anos e a política de incentivo ao credito para a compra de veículos, Manaus vem 
enfrentando problemas relacionados aos congestionamentos de trânsito, ainda que restritos à certos pontos da cidade e em apenas algumas horas do dia. Apresenta uma ligeira variação ao longo do ano, de modo que nos meses de janeiro e julho (período de férias), o trânsito melhora sensivelmente. A zona central de Manaus é a que tem o trânsito mais congestionado por apresentar serviços de convergência: comércio, escolas, agências bancárias, instituições públicas, feiras entre outros. Além desta há dois eixos viários onde os congestionamentos são mais frequentes: a) o eixo sul-norte representado pelas avenidas Constantino Nery, Djalma Batista e Torquato Tapajós que ligam o centro à zona norte da cidade e; b) o eixo leste-oeste representado pelas avenidas Darcy Vargas, Efigênio Sales, André Araújo e Cosme Ferreira.

\section{Temporalidades no Trânsito}

No trânsito assim como na vida o tempo, segundo Elias (1998), exerce uma função coercitiva de fora para dentro influenciando em nossa estrutura de personalidade. Estamos atrelados ao tempo macro (calendário) e micro (relógio) de várias formas:

Para obedecer ao estabelecido no Código de Trânsito Brasileiro (CTB) estaremos habilitados a dirigir um veículo no trânsito na idade mínima de 18 anos. Isso é o que nós definimos como tempo cronológico.

O tempo micro pode ser observado quando percorremos o espaço de um bairro a outro da cidade, de casa até o trabalho, de casa até a escola.

O tempo para se deslocar de barco entre as cidades amazônicas são contados em dias e não em quilômetros como normalmente são medidas as viagens em outras regiões do país. Esse tempo macro e micro é observado na mobilidade das estradas de rios da Amazônia. 
O ano do veículo para fins de emplacamento. Já para um colecionador de carro, o ano de um veículo tem um significado diferente de um usuário que tem o carro como um objeto de trabalho, lazer ou até mesmo status.

Horário de pico ou hora do rush, hora do dia em cidades grandes com tráfego intenso de veículos e congestionamentos nas ruas e estradas.

Tempo ocioso que o usuário fica sem fazer nada, dentro do carro, preso a um congestionamento. O tempo do semáforo.

Como podemos observar o tempo permeia as relações sociais e pode-se fazer sentir para mais ou para menos de forma coercitiva.

\section{O Trânsito de Manaus e a convergência de todos os tempos}

Não só Manaus, como outras cidades é possível notar a presença de grupos humanos com aspectos culturais diferentes, os quais se constituem forças poderosas de representações simbólicas. Onde é possível notar a influência de diversas culturas: alimentação, arquitetura, costumes, forma de vestir, artes, tradições. O transito se configura como uma convergência de todas essas culturas que no cotidiano são afetadas pela coerção do tempo. O tempo oferece padrão, uniformidade e repetição para a organização social onde percebe-se as rotinas diárias. Nesse sentido, reforçando Elias (1998), " tempo é símbolo de uma relação que um grupo estabelece entre dois ou mais processos, dentre os quais toma um, como quadro de referência ou medida para os demais". Na configuração do transito transitam indivíduos inseridos em redes de interdependências funcionais que integram o mesmo espaço com temporalidades diferentes.

Os carros podem estar mais potentes e velozes, mas os deslocamentos urbanos demoram cada vez mais em consequência dos congestionamentos e dos mecanismos de controle impostos pelo Estado 
para organizar o trânsito no qual o tempo do semáforo, o tempo do pedestre e os limites de velocidade são partes deste contexto.

Para o motorista de qualquer cidade do mundo, a luz vermelha do semáforo significa reduzir a velocidade, frear a cada quarteirão e perder tempo, para o pedestre que atravessa a faixa de pedestre o sinal vermelho significa alerta de segurança.

Para um motorista imprudente em qualquer cidade do Brasil o tempo que se ganha com a alta velocidade pode ser a vida que ele perde ou tira mais adiante.

Para estudante que sai atrasado de casa o sinal fechado significa perder o primeiro tempo de aula.

Para o trabalhador do Pólo Industrial de Manaus na parada do ônibus, tempo é produção, hora extra, já para o empresário tempo é dinheiro. E para o aposentado que bateu ponto a vida inteira, é tempo de desacelerar e recuperar o tempo gasto no trabalho.

Para o taxista o trânsito parado é corrida perdida. Para o caboclo do interior, o radar é o sol, o semáforo a lua, a estrada é o rio onde o trânsito flui e segue seu curso natural, sua rede social é a comunidade seu GPS a natureza.

\section{Considerações finais}

Regulador da vida em sociedade, organizador do nosso cotidiano, instrumento de integração, coordenação e controle social o tempo está mais presente em nossas ações e em redes cada vez mais complexas. Dessa forma, refletir sobre o tempo ajuda-nos a entender a dinâmica sóciohistórica de uma sociedade. Concebendo que o trânsito se dá pela relação de indivíduos interdependentes, o tempo onipresente em nossas vidas, permite-nos ampliar nosso olhar sobre as questões da mobilidade urbana, não tomando como único viés as estruturas e as questões econômicas. 


\section{Referências}

BAUMAN, Zygmunt. Modernidade Liquida; tradução Plinio Dentzien. Rio de Janeiro: Zahar, 2001

CÓDIGO BRASILEIRO DE TRÂNSITO. Ministério das Cidades, Conselho Nacional de Trânsito e Departamento Nacional de Trânsito. BRASÍLIA JULHO/2008.

ELIAS, Norbert. Sobre o tempo. Rio de Janeiro: Jorge Zahar, 1998.

O processo civilizador formação do estado e civilização (vol. 1), Rio de Janeiro: Jorge Zahar.I, 1990 [recurso eletrônico]

- Introdução à Sociologia, tradução: Maria Luísa Ribeiro

Ferreira, Lisboa: Ediçoes 70 Ltda, 2008

MANAUSTRANS. $\quad$ http://transito.manaus.am.gov.br/plano-degestao/ acesso em 06.09.2016

MARTINS, Mônica Mastrantônio. A questão do tempo para Norbert Elias: Reflexões atuais sobre tempo, subjetividade e interdiciplinaridade. In: Revista de Psicologia Social e Institucional. Volume 2 - Número 1 - Jun./2000

MATOS, Gláucio Campos Gomes de. Ethos e figurações na binterlândia amazônica. Manaus: Editora Valer/Fapeam, 2015.

Prefeitura Municipal de Manaus. Coordenação: SMTU, MANAUSTRANS e SEMINF. PLANO DE MOBILID ADE URBANA 2015.. Manaus: 2015. acesso em 05.08.2016 [recurso eletrônico]

RABUSKE, Edvino A. Antropologia filosófica: um estudo sistemático. 10.ed Petrópolis: Vozes, 1986. p.158-172.

REIS, José. O tempo de Heidegger. Revista Filosófica de Coimbra - n."28 (2005) [recurso eletrônico]

SANTOS, Eliane Barreto dos. $O$ espaço do trânsito http://www.transitobr.com.br/index2.php?id conteudo=118 acesso em 06.09.2016

SANTOS, Boaventura de Sousa. A grámatica do tempo: para uma nova cultura

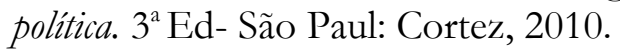

SILVA, José Maria da. Raça, desigualdade e o poder da representação na Amazônia. PRACS: Revista de Humanidades do Curso de Ciências Sociais UNIFAP. N. 1 dez 2008 [recurso eletrônico] 
SILVA, Nara Letycia Martins. O tempo social de Norbert Elias: uma proposta de superação ao conbecimento dicotômico do tempo. MNEME - Revista de Humanidades, 11 (27), 2010 Publicação do Departamento de História da Universidade Federal do Rio Grande do Norte. Centro de Ensino Superior do Seridó - Campus de Caicó. Semestral ISSN -1518-3394 Disponível em http://www.periodicos.ufrn.br/ojs/index.php/mneme

SOUZA, Geraldo Alves de. Espacialidade urbana, circulação e acidentes de trânsito: o caso de Manaus - AM (2000 a 2006) - Tese de Doutorado em Ciências em Engenharia de Transportes do Instituto Alberto Luiz Coimbra de Pós graduação e pesquisa de engenharia (COPPE) da Universidade Federal do Rio de Janeiro, 2009. 